\title{
Endometriose: Modelo Experimental em Ratas
}

\author{
Endometriosis: Experimental Model in Rats
}

Eduardo Schor, Vilmon de Freitas, José Maria Soares Júnior

Manuel de Jesus Simões, Edmund Chada Baracat

\begin{abstract}
RESUMO
Objetivo: divulgar a metodologia da indução de endometriose experimental em animais de laboratório.

Método: utilizamos ratas albinas, virgens, adultas de aproximadamente três meses de idade, que foram inicialmente anestesiadas pelo éter etílico. Aberta a cavidade abdominal, identificamos os cornos uterinos e retiramos um fragmento de aproximadamente $4 \mathrm{~cm}$ do corno uterino direito. Esse fragmento foi mergulhado em solução fisiológica e sob lupa estereoscópica foi separado o endométrio do miométrio e feitos retângulos de aproximadamente 4 por $5 \mathrm{~mm}$. Esses foram fixados por meio de fio de sutura, sobre vasos sangüineos visiveis a olho nu, na parede lateral do abdômen, tomando-se sempre o cuidado de manter a porção do endométrio livre voltada para a luz da cavidade abdominal. Após 21 dias os animais foram novamente operados para verificarmos o tamanho dos implantes $e$ para retirada do endométrio ectópico para análise histológica.

Resultados: macroscopicamente observamos crescimento significativo dos implantes endometriais. Ao exame microscópico pudemos observar a presença de epitélio glandular e estroma semelhantes ao do endométrio tópico.

Conclusões: o modelo utilizado reproduz a doença, em ratas, sendo método auxiliar de valia para estudar esta afecção, principalmente a ação de medicamentos sobre esses implantes.
\end{abstract}

PALAVRAS-CHAVE: Endometriose. Modelo experimental. Endométrio.

\section{Introdução}

A endometriose caracteriza-se pela presença de tecido endometrial fora da cavidade uterina ${ }^{1}$. É afecção que acomete mulheres em idade reprodutiva e se manifesta, na maioria das vezes, por dismenorréia, dispareunia, dor pélvica crônica ou infertilidade. O seu diagnóstico é feito por meio de exame histopatológico de material retirado em cirurgia, seja laparoscópica ou laparotômica. O fato

Setor de Algia Pélvica - Endometriose

Disciplina de Ginecologia

Universidade Federal de São Paulo - Escola Paulista de Medicina

Correspondência:

Eduardo Schor

Rua Mato Grosso, 128 cj 61 - Higienópolis,

01239-040 - São Paulo - SP da afecção necessitar de método invasivo para seu diagnóstico dificulta ou até mesmo impossibilita a realização de estudos controlados sobre o comportamento dos implantes de endométrio em face de diversos medicamentos. Assim, vários autores desenvolveram modelos experimentais de endometriose com a finalidade de observar a resposta do endométrio ectópico a diferentes esquemas terapêticos e seu comportamento durante a gestação, bem como a sua relação com a fecundidade e os eventuais efeitos histológicos e bioquímicos ${ }^{2,3,4,5}$.

Vários modelos foram propostos com esta finalidade como o de Schenken e Asch ${ }^{2}$, em 1980, que desenvolveram endometriose em coelhas, retirando fragmentos de endométrio e implantandoos no peritônio. Jones ${ }^{3}$ utilizou, pela primeira vez, 
ratas para o estudo da endometriose. Conseguiu reproduzir a doença fixando fragmentos de endométrio retirados do corno uterino à parede lateral do abdome. Sakata et al. ${ }^{6}$, em 1990, também utilizaram ratas para o estudo da doença, porém, implantaram fragmentos de endométrio sob a cápsula renal dos animais.

Vernon e Wilson ${ }^{4}$ utilizaram ratas com o objetivo de estudar o efeito da endometriose na gestação, e comparar o teor de prostaglandinas no endométrio ectópico com o do tópico. Implantaram pequenos fragmentos de endométrio no mesentério e no ligamento útero-ovárico desses animais. Rock et al. ${ }^{5}$, por sua vez, implantaram fragmentos de endométrio e de endometriose de mulheres, além de endométrio do próprio animal, no globo ocular de coelhas. Notaram que houve rejeição do tecido humano, porém, o fragmento de endométrio da própria coelha desenvolveu-se e mostrou alterações macroscópicas a diferentes concentrações de estrogênio, administrado sob a forma de implantes subcutâneos. Acreditam ser, este modelo, válido para o estudo do comportamento do tecido endometrial ectópico aos diferentes agentes terapêuticos.

Outros modelos animais também foram utilizados para o estudo da endometriose. D'Hooghe et al. ${ }^{7}$, desenvolveram um modelo de menstruação retrógrada em primatas (Papio cynocephalus). É o que mais se aproxima do observado na espécie humana, contudo, os custos de manutenção e a dificuldade de obtenção dos animais tornam este modelo pouco acessivel.

O intuito de nosso trabalho é avaliar a reprodutibilidade, em nosso meio, do modelo experimental proposto por Jones em $1984^{3}$.

\section{Material e Métodos}

Utilizaram-se 40 ratas albinas (Rattus norvegicus albinus, Rodentia, Mammalia) adultas, com 90 dias de idade, virgens, pesando aproximadamente $200 \mathrm{~g}$, da linhagem Wistar EPM- $1^{1}$, procedentes do CEDEME da Universidade Federal de São Paulo - Escola Paulista de Medicina (UNIFESP-EPM).

Após um período de adaptação de, aproximadamente, uma semana, a endometriose, foi induzida, em todos os animais, consoante a metodologia preconizada por Jones ${ }^{3}$. Para tanto, os animais foram inicialmente anestesiados em campânula saturada com vapores de éter etílico; a seguir, por tração manual, foram retirados os pêlos da região abdominal, sendo esta lavada com soro fisiológico. Em seguida, a cavidade abdominal foi aberta por incisão longitudinal de cerca de $2 \mathrm{~cm}$ na linha alba e identificados os cornos uterinos. Após a sua individualização, ressecou-se aproximadamente $4 \mathrm{~cm}$ do terço médio do corno uterino direito, após ligadura dos vasos sangüíneos. O segmento uterino retirado foi imediatamente imerso em soro fisiológico a $4^{\circ} \mathrm{C}$; em seguida, foi aberto longitudinalmente e separada a região do endométrio, com o auxilio de uma lupa estereoscópica. Em seqüência, o endométrio foi fragmentado em retângulos medindo 4 por $5 \mathrm{~mm}$. Estes fragmentos (implantes) foram fixados dois de cada lado da linha alba na parede abdominal, sempre no local em que havia vasos sangüineos bem visiveis, com o auxílio de um fio de sutura de Nylon 6.0, tomando-se sempre o cuidado de manter a porção de endométrio livre voltada para a luz da cavidade abdominal.

Após estes procedimentos, a cavidade abdominal foi suturada em dois planos: o muscular com pontos contínuos e, o da pele, com pontos separados de fio de algodão.

Vinte e um dias após a indução da doença, na fase de estro, os animais foram novamente anestesiados com vapores de éter etílico, e fez-se incisão longitudinal mediana xifo-púbica. Após a abertura da cavidade abdominal, identificaram-se os locais dos implantes e imediatamente foram realizadas medições da área dos implantes (comprimento x largura), com o auxílio de um paquímetro (Mora).

A seguir os implantes foram retirados, fixados em formol a $10 \%$ e processados para inclusão em parafina. Realizaram-se cortes dos blocos que foram corados pela hematoxilina e eosina (HE) e pelo tricrômico de Masson para análise morfológica.

\section{Resultados}

Em todos os animais notamos, após 21 dias da fixação (implante) dos fragmentos de endométrio na parede abdominal, desenvolvimento e crescimento dos implantes (endometriose) (Figura 1). Deve ser mencionado que na maioria dos animais houve o desenvolvimento de cistos.

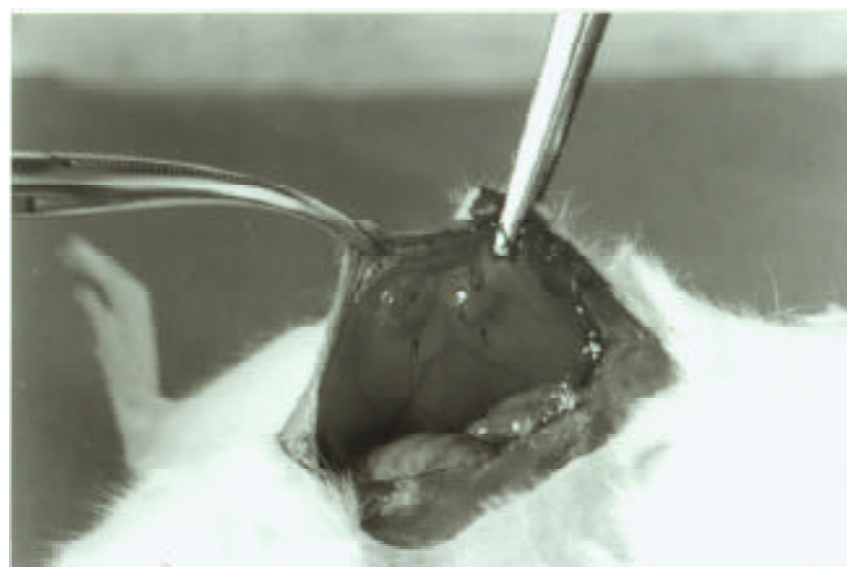

Figura 1 - Fotografia mostrando dois implantes de endométrio (setas) na parede abdominal de rata adulta 21 dias após a indução. 
Os valores das médias das áreas dos implantes do endométrio 21 dias após os implantes encontram-se representados no Figura 2. Como se observa, houve aumento significativo do tamanho dos implantes após 21 dias da indução.

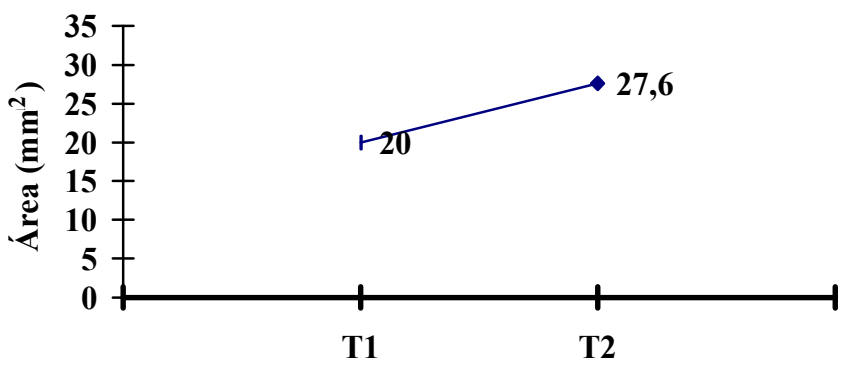

Tempo do experimento

Figura 2 - Média dos valores das áreas dos implantes nos dois tempos do experimento (T1, momento do implante e T2, 21 dias após o implante). T2>T1 ( $p=0,0430)$.

Microscopicamente, os implantes apresentavam cistos volumosos, de parede delgada, lisa, localizados sobre a musculatura estriada da parede abdominal, fazendo saliência para a cavidade peritoneal. As paredes dos cistos achavam-se constituidas por delgada camada de tecido conjuntivo, rico em células, revestidas internamente por epitélio pavimentoso simples. Em alguns casos, o implante mostrava arquitetura semelhante à do endométrio típico da fase de estro, ou seja, epitélio de revestimento constituído por células cúbicas ou ligeiramente prismáticas com núcleo eucromático, e nucléolo bem evidente. Nestas células, epiteliais de revestimento, notamse ainda figuras de mitose típicas. O estroma mostra grande quantidade de fibroblastos bem desenvolvidos, alguns macrófagos, com pigmentos de hemossiderina no seu interior, além de plasmócitos e leucócitos do tipo eosinófilo. Notávamos ainda no estroma, grande concentração de glândulas endometriais típicas revestidas por epitélio cúbico ou cilíndrico simples (Figura 3).

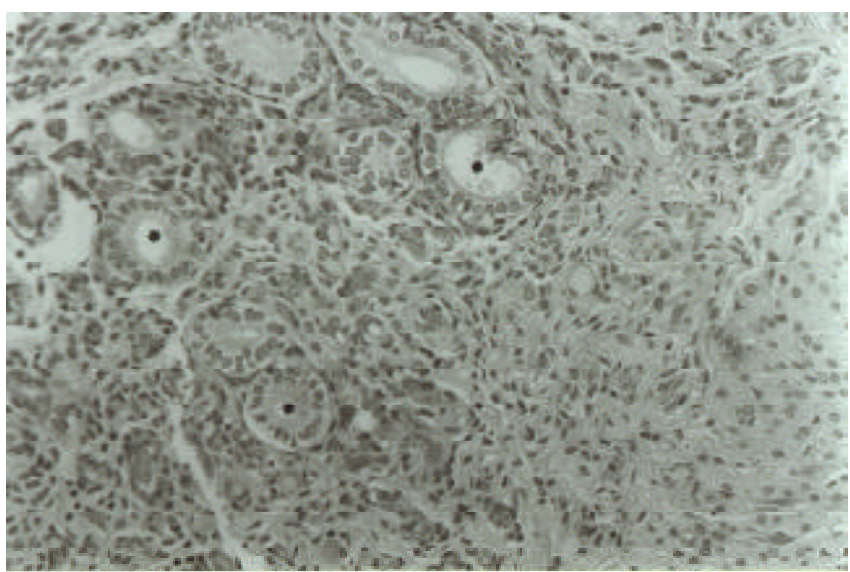

Figura 3 - Fotomicrografia mostrando parte do implante do endométrio 21 dias após a indução. Nota-se endométrio revestido por epitélio cilíndrico simples e glândulas endometriais $\left(^{*}\right)$. Há, no estroma, macrófagos contendo pigmentos de hemossiderina (seta). $\mathrm{HE}, \pm 210 \mathrm{X}$

\section{Discussão}

Com o propósito de melhor estudar a endometriose, como também o comportamento da doença em face de vários esquemas terapêuticos, procuramos mostrar como é possivel reproduzi-la em modelo animal. Conforme foi mencionado na Introdução é possivel se induzir a endometriose em vários animais, mas escolhemos a rata, por ser um animal amplamente estudado na literatura e muito resistente às infecções, não necessitando do uso de antibióticos. Em nosso experimento observamos no início alguns processos infecciosos. No entanto, com o decorrer do experimento e tomando sempre o cuidado de limpar bem o material cirúrgico não ocorreu mais nenhum destes casos. Deve ser mencionado que alguns autores preconizam o uso de antibióticos após o procedimento cirúrgico, não sendo esse nosso protocolo.

Vários modelos existentes foram, reproduzidos na literatura, mostraram-se eficientes em simular a endometriose. Optamos pelo modelo proposto por Jones ${ }^{3}$ por entendermos que as medidas de área, dado fundamental para nossas conclusões, seriam obtidas com maior facilidade sobre a parede abdominal do que sob a cápsula renal ou sobre o ligamento útero-ovárico. Ademais este modelo pareceu-nos o mais adequado tanto pela reprodutibilidade quanto pela aceitação na literatura.

Após a indução da endometriose observamos que houve crescimento significativo dos implantes três semanas após a sua indução. Tal achado foi também relatado por diversos autores ${ }^{2,5,8,9,10,11}$. Ao exame microscópico registramos a presença de células glandulares e estromais semelhantes às do endométrio tópico, o que nos leva a crer que o tecido implantado conservou após 21 dias suas características originais. Além disso, revelou também atividade secretora, caracterizada pela formação de cistos sobre o implante.

Diante desses resultados acreditamos que o modelo por nós utilizados foi capaz de reproduzir as características morfológicas da endometriose, podendo auxiliar no estudo desta afecção.

Deve ser enfatizado que este modelo estuda fragmentos de endométrio normal implantados na parede abdominal. Apesar da literatura referir como sendo pontos de endometriose, a rigor não se pode afirmar que esses fragmentos implantados se comportam como pontos de endometriose verdadeira, mas acreditamos que muito se pode aprender com este modelo que é de fácil execução e que pode ser submetido a vários tratamentos experimentais. 


\section{SUMMARY}

Purpose: to demonstrate the experimental endometriosis induction in animals.

Method: we used adult female Wistar rats weighing $200-250 \mathrm{~g}$ anesthetized with ethyl ether to open the abdominal cavity. After identifying the uterine horns, we removed an approximately 4 $\mathrm{cm}$ fragment from the right uterine horn. This fragment was placed in physiological saline and, with the aid of a stereoscopic magnifying glass, the endometrium was separated from the myometrium and cut into rectangles of approximately $4 \times 5$ $\mathrm{mm}$. These rectangles were fastened to the lateral abdominal wall near great blood vessels, taking care that the free portion of the endometrium was directed towards the lumen of the abdominal cavity. After 21 days the animals were again operated to observe the size of the implants and to remove the ectopic endometrium for microscopic analysis.

Results: we macroscopically observed a significant growth of the endometrial implants. Microscopic examination showed presence of glandular epithelium and stroma similar to topic epithelium.

Conclusion: this model reproduces endometriosis in the female rat allowing a better study of this pathology, mainly the action of drugs on these implants.

KEY WORDS: Endometriosis. Female rats. Experimental model

\section{Referências}

1. Rodrigues de Lima G, Freitas V., Zamith R. Aspectos endócrinos da endometriose. In: Rodrigues de Lima G, Baracat EC, editores. Ginecologia Endócrina. Atheneu: São Paulo, 1995. p. 209-20.

2. Schenken RS, Asch RH. Surgical induction of endometriosis in the rabbit: Effects on fertility and concentration of fluid periotneal prostaglandins. Fertil Steril 1980;34:581-7.
3. Jones RC. The effect of a luteinizing hormone releasing hormone agonist (Wy-40, 972), levonorgestrel, danazol, and ovariectomy on experimental endometriosis in the rat. Acta Endocrinol 1984; 106:282-8.

4. Vernon MW Wilson, EA. Studies on the surgical induction of endometriosis in the rat. Fertil Steril 1985;44:684-7.

5. Rock JA, Prendergast RA, Bobbie D, Green WR, Parmley TH, Dubin NH. Intraocular endometrium in the rabbit as a model for endometriosis. Fertil Steril 1993;59:232-5.

6. Sakata M, Terakawa N, Mizutani T, Tanizawa O, Matsumoto K, Terada N, Sudo K. Effects of danazol, gonadotropin releasing hormone agonist, and a combination of danazol and gonadotropinreleasing hormone agonist on experimental endometriosis. Am J Obstet Gynecol 1990;163:1679-84.

7. D'Hooghe TM, Bambra CS, Raeymaekers BM, Koninckx, PR. Development of spontaneous endometriosis in baboons. Obstet Gynecol 1996;88:462-6.

8. Rajkumar K, Schott PW, Simpson CW. The rat as an animal model for endometriosis to examine recurrence of ectopic endometrial tissue after regression. Fertil Steril 1990;53:921-4.

9. Tjaden BG, Woodruff D, Galetto JW, Rock R. Time related effects of RU-486 treatment in experimentally induced endometriosis in the rat. Fertil Steril 1993;59:437-40.

10.Zanagnolo VLB, Beck R, Schlaff, WD, Damewood, MD. Time-related effects of a gonadotropinreleasing hormone analog treatment in experimentally induced endometriosis in the rat. Fertil Steril 1991;55:411-4.

11.Zanella SRT, Tsuruda RH, Guzzoni SR Trautwein V W, Beck R T. Tratamento com agonista do GnRH a partir de lesão induzida em ratas. Rev Bras Ginecol Obstet 1994;16:125-7. 